\title{
Timing of Mental Illness Onset and Motherhood
}

\author{
Carol T. Mowbray, PhD, * Deborah Bybee, PhD, $†$ Daphna Oyserman, PhD,, \\ and Peter MacFarlane, $B S^{*}$
}

\begin{abstract}
The timing of mental illness onset in relationship to birth of children was explored as a possible indicator of the extent to which mothers experienced difficulties in parenting and functioning. Analyses employed data from a longitudinal study of urban-based, primarily minority mothers with mental illness $(N=379)$ who had parenting responsibility for their minor children. We found that women who were parents first and experienced mental illness onset after the birth of all their children showed the most positive trajectories over the study course. Mothers whose mental illness onset occurred before the birth of any of their children also showed improvements in functioning and symptomatology over time. In contrast, mothers whose mental illness onset had occurred in temporal proximity to the birth of a child showed little improvement. They also were younger, on average, at first birth, and had the largest number of children. Thus, timing of mental illness onset and childbirth may be predictive of longer-term maternal functioning and therefore may be useful in clinical assessment and treatment.
\end{abstract}

Key Words: Postpartum psychosis, serious mental illness, mothers, mental illness onset, postpartum depression.

( Nerv Ment Dis 2005;193: 369-378)

$\mathrm{D}$ ue to increased availability of community-based mental health treatment/rehabilitation methods and advances in psychopharmacy, women with serious mental illnesses (MIs) are more likely to be mothers and to carry out parenting responsibilities (Nicholson et al., 2001). Unfortunately, multiple parenting problems have been repeatedly identified for mothers with MI compared with nonmentally ill controls:

*School of Social Work, University of Michigan, Ann Arbor, Michigan; $\dagger$ Department of Psychology, Michigan State University, East Lansing, Michigan; and $\ddagger$ Institute for Social Research, Department of Psychology, and School of Social Work, University of Michigan, Ann Arbor, Michigan.

Supported by a grant from the National Institute of Mental Health, \#R01MH54321, "Seriously Mentally Ill Women: Coping With Parenthood," to the first and third authors.

Send reprint requests to Carol T. Mowbray, $\mathrm{PhD}$, University of Michigan School of Social Work, 1080 S. University Ave., Rm 2734, Ann Arbor, MI 48109-1106.

Copyright (C) 2005 by Lippincott Williams \& Wilkins

ISSN: 0022-3018/05/19306-0369

DOI: $10.1097 / 01 . n m d .0000165088 .82453 . b d$ for example, being more negative toward children (InoffGermain et al., 1997), more critical (Gordon et al., 1989), and less responsive in their parenting (Beardslee et al., 1997). However, according to a recent comprehensive review of parenting among mothers with serious MI (SMI; Oyserman et al., 2000), research to date has failed to identify the variables that specifically predict parenting problems. That is, not all parents with MI have problems, but neither parenting strengths nor deficits have been consistently related to diagnoses, symptom severity, chronicity of MI, or level of community functioning.

In the current article, we explore the notion that certain women may be at greater risk for parenting problems, based on the timing of onset of MI relative to motherhood - that is, whether a woman experiences early onset of MI and later becomes a mother, or has children and then experiences mental illness, or first experiences her serious mental illness in temporal proximity to the birth of a child. We believe that timing of MI onset vis-à-vis childbirth is important, based on several streams of evidence.

First, the issue of timing-whether an individual has had a chance to become experienced in a particular role prior to the onset of MI-has been well-researched for another important adult social role, that of worker. In psychiatric rehabilitation practice, one of the strongest and most consistent predictors of successful vocational outcomes for adults with SMI has been occupational performance before MI onset (e.g., work experience, work skills, previous employment history, work adjustment, and so forth; Tsang et al., 2000). Based on this research, we would expect that mothers will function better as parents when they have experience in parenting followed by MI onset, rather than the reversewhen MI onset precedes parenting.

In regard to MI onset temporally associated with childbirth, psychoanalytically oriented scholars would predict that children born within 12 months of the mother's MI onset should have poorer outcomes than those born 2 or more years after (Vartiovaara et al., 1990), due to permanent disruption of mother-child bonding and impairment of parenting behaviors. Similar conclusions can be drawn from stress researchers who have demonstrated that early childhood experiences of stress and adversity (including prenatal) have long-term 
and severe carry-forward effects on children's functioning (Rutter, 1994). Research on postpartum depression has documented negative effects on children's outcomes (Philipps and O'Hara, 1991; Righetti-Veltema et al., 2002). Since the functioning and well-being of children and parents are reciprocal, infant problems would likely have long-term effects on mothers' parenting and her overall outcomes.

\section{REVIEW OF EMPIRICAL STUDIES}

Interestingly, the effects of mothers' experiencing MI onset before versus after their children are born have not been examined systematically to any significant extent. In fact, many studies on the parenting problems of mothers with SMI do not provide any information at all on whether MI onset occurred before or after having children (see, for example, Goodman and Brumley, 1990; Goodman et al., 1994). There is a substantial literature on postpartum depression and psychosis and how these disorders affect maternal functioning and parenting. However, many of these studies include women who actually first experienced MI episodes before the pregnancy being studied (e.g., in Robling et al., 2000, 25\% of the sample had a previous episode). Also, pre/postpartum studies often fail to note whether the psychiatric illness began at the birth of the first or subsequent children. This may lead many clinicians to mistakenly assume that if a postpartum disorder had not occurred with the first childbirth, it would not occur at all, and to fail to monitor the woman's functioning carefully during and after subsequent pregnancies. Research demonstrates that postpartum disorders are frequently first experienced in second or later pregnancies: in Pfuhlmann et al. (1999), the sample contained $77 \%$ primiparae, $19 \%$ having their second child, and $4 \%$ having a third delivery. For women admitted to a psychiatric mother-baby unit, Hipwell and Kumar (1996) reported primiparity for $53 \%$ to $69 \%$ of their sample, depending on diagnosis.

Despite the potential significance of the timing relationship between MI onset and birth of children, we were able to locate only a few studies that directly compared mothers who experienced onset of their MI before birth of any children, versus after all their children were born, versus in proximity to the birth of a child. These studies did identify differences in mothers' demographics and clinical characteristics. In one report, women whose MI onset occurred close in time (versus unrelated) to the experience of childbirth were more often white and more likely to have an affective disorder diagnosis (Wisner et al., 1995). Another study of women with psychiatric illness admitted to a mother-baby unit contrasted those with MI onset before the child's birth (having had a previous psychiatric episode) versus those having a childbirth-related onset; the latter group was more likely to have their infants placed in foster care (Hipwell and Kumar, 1996). Similarly, in a London study of all first-time pregnant women attending an obstetric clinic, children whose mothers became depressed within the child's first year (versus later) showed significant intellectual deficits (Cogill et al., 1986). Another study using the same design, but a different sample, reported similar results (but for boys only), even with controls for confounding factors at birth (Sharp et al., 1995).

Puckering (1989) suggested that mothers who first experience depression in conjunction with childbirth have more difficulties interacting with infants than mothers who have had prior depression episodes. However, in a US study of 450 low-income women diagnosed with major depressive disorder (Broitman et al., 2001), there were no differences in children's adaptive functioning or behavior problems based on whether mothers experienced a depressive episode before the child was born or in its first year of life, versus laterwhen the child was a toddler or school-age. A difficulty with this study is that MI onset before childbirth and MI onset in the postpartum period were not separated. The major problem with the literature overall is that most studies have not collected data on the timing issue.

The current study compares the characteristics and functioning of mothers who have SMI and who differ in the timing of their MI onset vis-à-vis birth of their children. We compare women whose MI onset predated by several years the birth of any children, those who first had one or more children and several years later experienced MI onset, and women for whom MI onset occurred proximal in time to the birth of a child. The data come from an NIMH-funded study of mothers with SMI, recruited from the public mental health system in a large urban area. Study results are intended to provide information on the sequence of MI and motherhood and to explore whether the timing of MI onset versus childbirth could serve as a risk indicator for impairment of mothers' functioning and/or parenting. Such information can be important in assisting mental health providers be more prepared to serve these women and their children appropriately. Based on the literature reviewed, we examined outcomes (functioning, symptomatology, and parenting) of women experiencing the onset of their MI before childbirth, and women having borne all their children and then experiencing MI onset, versus those women with MI onset proximal to the birth of a child. Because the course of severe MI is known to be highly variable (Fenton, 2000; Strauss et al., 1985), we examined maternal variables at baseline as well as trajectories over time. We include controls for age of mothers at MI onset, since the literature suggests that adults with early onset of SMI (e.g., under age 21) may differ significantly from those with adult onset (for affective disorders, see Greden, 2001; for schizophrenia, see Jacobsen and Rapoport, 1998). 


\section{METHODS}

\section{Sample}

Participants are from a longitudinal, NIMH-funded study of mothers with SMIs (Mowbray et al., 2000) systematically recruited from $12 \mathrm{CMH}$ Centers and inpatient psychiatric units of three hospitals in southeastern Michigan. All eligible participants on the agency rolls were identified by a research project liaison, using information from agency staff and/or management information systems. Eligible women were 18 to 55 years of age, were seriously mentally ill, had primary care responsibilities for at least one child aged 4 to 16 , and had an active case at study initiation. Of 485 women identified, 46 could not be contacted or scheduled, and 59 refused to be involved. Thus, 380 women were enrolled (78.4\%). One woman died between time of enrollment and the scheduled interview, leaving 379 participants.

Participants' mean age was 36.50 years $(S D=6.61)$. The median number of children was three, with a median age of 11 years. Slightly over half of women were African American (59.9\%), 29.3\% were Caucasian, 7.9\% were Hispanic, and $2.9 \%$ were of other racial/ethnic backgrounds. For $35.1 \%$, highest education was under 12 years, $25.1 \%$ completed high school, and $39.8 \%$ had more than high school. The largest group of women (48.0\%) lived alone with their children, $32.2 \%$ lived with a spouse/partner and children, $14.8 \%$ lived with extended family and children, and 5.0\% lived alone without their children, although they had at least weekly care responsibilities. Median family income was $\$ 929 /$ mo. Adjusting for household composition, $68.1 \%$ fell below the federal poverty threshold for the baseline period (1996; US Bureau of the Census, 1997).

Mean age of onset of MI in this sample was 26.7 years $(S D=8.21)$. Time since MI onset ranged from 1 to 34 years $(M=10.38 ; S D=7.54)$. Mean number of psychiatric hospitalizations was $4.24(S D=7.44 ; M d n=2)$. In the year before the interview, about one third of the women had a psychiatric hospitalization. Of the 379 participants, 337 met DSM IV criteria as follows: schizophrenia (10.4\%), schizoaffective (10.1\%), major depression (51.7\%), and bipolar disorder $(27.9 \%)$. The 42 women ( $11.1 \%$ of the total) with no research diagnosis included 14 who did not complete the diagnostic interview and 28 with insufficient information for diagnosis.

\section{Procedures}

Three sets of interviews were conducted with each participant, about 20 months apart: W1 was the baseline interview; W2 and W3 were follow-up interviews. All interviews took place in participants' homes, and women were compensated for each interview. The completion rate was $87.1 \%$ at $\mathrm{W} 2$ and $87.5 \%$ at $\mathrm{W} 3$. The total number of women who participated in at least two waves was 343 or $92.3 \%$ of the living sample.

\section{Measures \\ Descriptive Variables}

\section{Demographics and Background}

Women were asked their age, race, number of children, highest education, children's birth dates, marital status, living arrangements, income, and family SES.

\section{Psychiatric History and Service}

Items included age at MI onset, duration of MI, and psychiatric hospitalizations (number in the prior year and lifetime). Hospitalization variables were log-transformed to minimize skew, a common practice for count variables (Fox, 1997). Psychiatric history was obtained through a Life History Calendar to maximize respondents' recall. Lifetime diagnoses were determined at W1. Modules from the Diagnostic Interview Schedule (Robins et al., 1981) were administered by trained interviewers. Diagnostic determinations were made by two trained clinicians, based on written interview data and taped interviews, on a consensus basis. Respondents were asked about psychiatric service use in the last 3 months; data from the separate questions were compiled to produce a 6-point ordinal scale for level and intensity of services, ranging from $0=$ no formal mental health services to $5=$ case management weekly $(M=3.18 ; S D=1.59)$. Service satisfaction was based on the Client/Patient Satisfaction Questionnaire (AAPH, 1994; nine items; 4-point scale from $1=$ not at all to $4=$ quite a bit; $M=2.92 ; S D=0.51$; $\alpha=.82$ ). Women were also asked about need for services (W2, nine items, 4-point scale from $1=$ not at all to $4=$ quite a bit; $M=1.88 ; S D=0.67 ; \alpha=.78$ ).

\section{Outcome Variables}

\section{Symptomatology and Functioning}

The Colorado Symptom Index (Shern et al., 1994), a 14-item, 5-point response scale $(1=$ never/not at all in the last year to $5=$ at least every day/most of the time) was administered at each wave (W1, $M=2.77, S D=0.83$; W2, $M=2.58, S D=0.78$; W3, $M=2.52, S D=0.79 ; \alpha=$ 90-.91). The Community Functioning Scale (Bybee et al., 2003), an 18-item, 5-point scale ( $1=$ no activity in domain to $5=$ frequent independent activity) was also used at each wave, to assess activities of daily living, medication and symptom management, and interpersonal relations (W1, $M=$ 3.37, $S D=0.54$; W2, $M=3.53, S D=0.54$; W3, $M=3.48$, $S D=0.56 ; \alpha=.78-.80)$. The mean scores indicated that, overall, most women were able to function in their communities, requiring only "some assistance." 


\section{Parenting}

Measures included parenting stress (Abidin and Wilfong, 1989; 14-item, 5 -point scale from $1=$ not at all to $5=$ very much; $M=2.52 ; S D=0.78 ; \alpha=.86$ ); nurturance (subscale of the Block Child Rearing Practices scale, Rickel and Biasatti, 1982; 13-item, 4-point scale from $1=$ not at all to $4=$ very much; $M=3.66 ; S D=0.33 ; \alpha=.80$ ); and parenting satisfaction with mother-child relationship (Gibaud-Wallston and Wandersman, 1978; 8-item, 5-point scale from $1=$ very dissatisfied to $5=$ very satisfied; $M=$ 4.0; $S D=0.80 ; \alpha=.84)$. Measures of parenting support came from the Arizona Social Support Interview Schedule (Barrera, 1986), asking participants to list people important to them and perceived available and used (enacted) for childcare support or for providing parenting feedback ${ }^{1}$ : available SS child care: $M=2.65, S D=1.65$; enacted SS child care: $M=1.92, S D=1.23$; available SS parenting feedback: $M=$ 2.56, $S D=1.88$; enacted SS parenting feedback: $M=2.11$, $S D=1.63$. Following Baumrind's (1991) theory, explanatory parenting style was coded from women's responses to four parenting scenarios $(M=2.22 ; S D=1.18 ; \kappa=.75)$. Finally, the meaning of motherhood was obtained with six open-ended questions coded on 10 variables, such as negativity, restrictiveness, children as resources, and so forth. We conducted an exploratory factor analysis (varimax rotation) of these variables, which revealed three parent self-construal factors, explaining $56 \%$ of the item variance: feeling positive/ efficacious about parenting, seeing the child as a burden, and viewing parenting as providing nurturance and personal growth for the mother (Oyserman et al., 2004).

\section{Determination of MI Onset Versus Childbirth}

Time of MI onset was determined from respondents' answers to questions on the life history calendar: women were asked about the year of their first MI hospitalization. Those with no hospitalizations were then asked for the year they first saw a MH professional. Finally, those few women who neither had a psychiatric hospitalization nor saw a mental health professional were asked for the year they were first prescribed psychotropic medication. Women answered about the year in which one of the above occurred; however, children's births had specific calendar dates. To accommodate potential rounding errors, we used 18 months before or after a child's birth as a criterion for MI onset proximal to the birth of a child. To examine the temporal relationship between MI onset and the birth dates of each mother's children,

${ }^{1}$ Internal consistency reliability is not reported for the social support measures, since they are counts of persons supplying certain types of support. As indicators rather than items that are manifestations of an underlying hypothetical construct, they do not meet the criteria of classical test theory and therefore are not appropriate for internal consistency statistics (Streiner, 2003). women were placed in one of three groups: $1=$ all births at least 18 months after MI onset, 2 = all births at least 18 months before MI onset, and 3 = birth of any child proximal to MI onset ( \pm 18 months). A fourth group, MI onset between two births but not within 18 months of either, was relatively small $(N=36)$; since it had not been identified in previous research studies, did not appear to be clinically significant, and possibly reflected rounding errors, it was dropped from further analyses.

\section{Analysis Plan}

Statistical analyses first examined the three constructed groups reflecting timing of MI onset versus motherhood for differences on demographic, psychiatric history/services, parenting, functioning, and symptomatology measures, using analysis of variance for continuous dependent variables and $\chi^{2}$ for categorical variables. All univariate analyses used modified Bonferroni adjustments (Jaccard and Wan, 1996) to ensure that multiple comparisons did not inflate the likelihood of obtaining significant differences by chance. Multilevel modeling (MLM; Bryk and Raudenbush, 1992) was used to test for differences among the groups in changes over time on outcome variables (parenting, community functioning, and symptomatology). MLM characterizes patterns of change by estimating individual-level intercepts and slopes, which can be modeled as random functions of other, explanatory variables. The method allows cases with partially missing data to be included in the analysis, and it allows accurate specification of the timing of data collection rather than assuming interviews occurred at exactly equivalent intervals. In the MLM analyses, the group identification was entered as two dummy-coded variables, with the onset proximal to motherhood group as the omitted comparison category. The W1 interview was specified as the intercept, and time of each interview was calculated as the number of days from the W1 interview, divided by 364.25 to define the metric in years. Because MI often takes a nonlinear course, combining periods of rapid change with plateaus of relative stability (Harding and Keller, 1998), the analysis tested for the significance of a nonlinear (quadratic) slope reflecting acceleration or deceleration in change. With three measurement points, the quadratic slope was limited to a fixed effect (i.e., it could not vary across individuals). Nonetheless, when addition of the nonlinear slope significantly improved model fit relative to the linear model, it served to avoid bias in the estimated effects of other explanatory variables (Stoolmiller et al., 1993).

\section{RESULTS}

Data from 377 women in the study sample were used in the analyses (two women could not recall the birth dates of all their children). The number of women in each of the categories developed for this study is as follows: MI onset before all 
births, 78 (20.7\%); parenting (all births) before MI onset, 154 (40.8\%); MI onset proximal to pregnancy or delivery, 109 (28.9\%). As previously indicated, a fourth group $(9.5 \%$ of the sample) was dropped from further analyses. For women whose MI onset occurred before the birth of any child, their first child was born, on average, 5.7 years after their MI onset $(M d n=4.91 ; S D=3.58 ;$ range $=2-17$ years $)$. For women parenting before MI onset, the onset occurred, on average, when their last child was 7.0 years $(M d n=6.20 ; S D=4.08$; range $=2-20$ ). For women in the proximal category, MI onset occurred within 18 months of the birth of a child as follows: first child, 36 (33.0\%); second child, 34 (31.2\%); third child, 25 (22.9\%); fourth child, nine (8.3\%); fifth or later child, five $(4.6 \%)$. In exploratory analyses, we found that about two thirds of the women in the proximal category went on to have subsequent pregnancies. These women were significantly less educated $(21.2 \%$ vs. $48.7 \%$ less than high school; $\left.\chi_{[2, N=109]}^{2}=7.23 ; p<0.03\right)$, younger $(M=33.7$ vs. $37.7 ; t[107]=2.89 ; p<0.01)$, and younger at their MI onset $(M=22.7$ vs. $28.8 ; t[106]=5.12 ; p<0.01)$ than those who stopped having children after the onset of MI.

\section{Differences Across Groups on Demographics, Psychiatric History, and Service Variables}

Table 1 presents ANOVA and $\chi^{2}$ test results comparing the three groups (MI first, parenting first, onset proximal to childbirth) on descriptive variables. Significant differences were identified for age, age at first birth, age at MI onset, duration of MI, race, education, differences between education of the respondent and her mother, marital status, number of children, diagnosis, number of lifetime hospitalizations, and services needed at W2. The parenting-first group was significantly older than the other two groups at data collection, but the MI-first group was significantly older than the others when their first child was born and also had higher education levels. These demographic differences might be expected. Because they could be confounded with clinical variables, we used them as controls in subsequent analyses. Other differences included the fact that respondents' education and their mothers' education levels were significantly greater for the parenting-first group compared with the proximal-onset group; in the latter, the educational attainment of study respondents and their mothers were much more similar, even after controlling for race. The parenting-first group was more likely to have ever married or to be living with a partner compared with the MI-first group. The proximal-onset group had disproportionately more African Americans than the parenting-first group and significantly more children than the other two groups.

In terms of psychiatric history, mothers with MI first were more likely to have a diagnosis of schizophrenia/

TABLE 1. Significant Differences Across Descriptive Variables at Baseline for MI Onset vis-à-vis Childbirth Groups

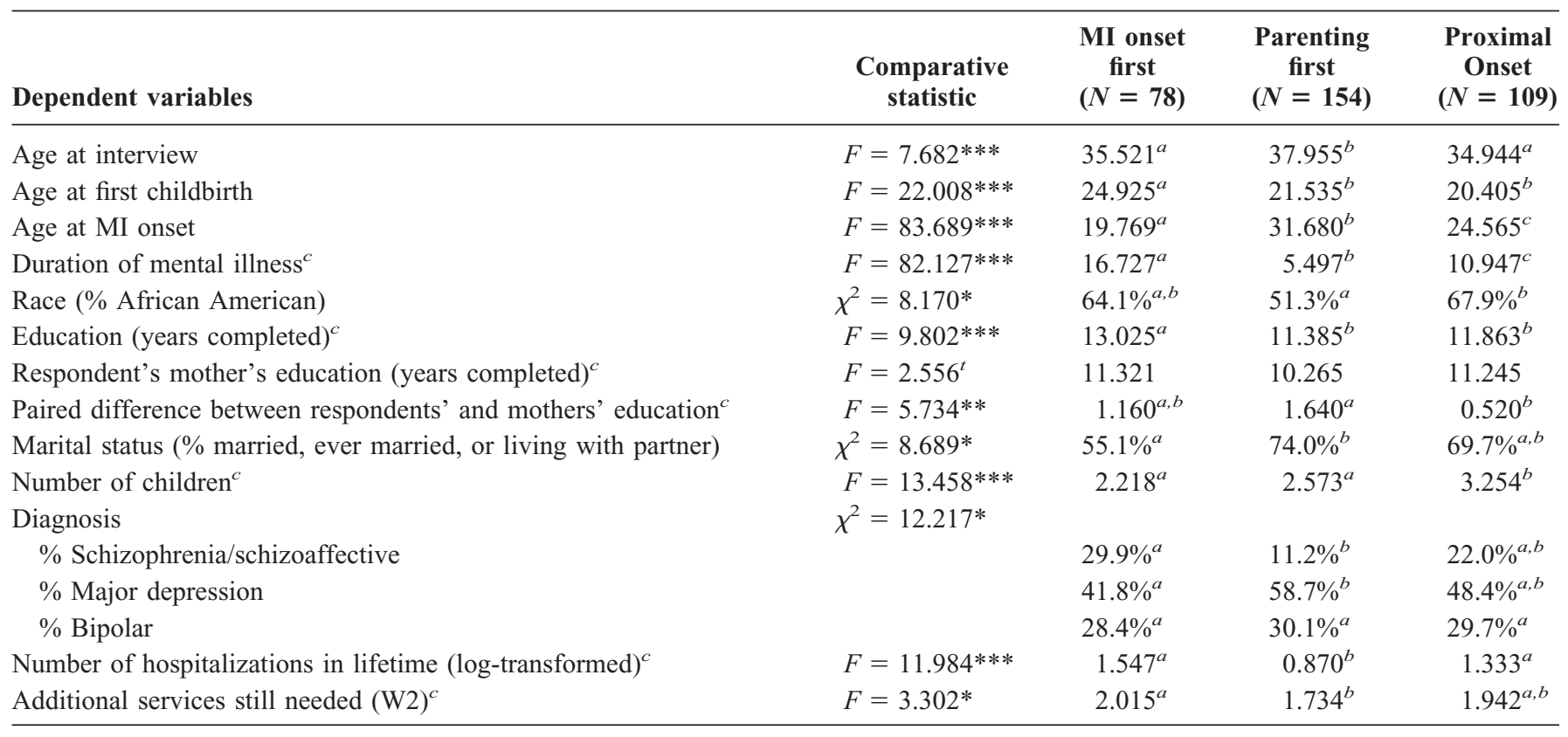

${ }^{*} p<0.05 ; * *<<0.01 ; * * * p 0.001$.

${ }^{a, b}$ Within each row, cell means with different superscripts are significantly different at Bonferroni-adjusted $p<0.05$.

${ }^{c}$ Controlled for age of respondent at time of MI onset.

${ }^{\mathrm{t}} \mathrm{pt}<.10$. 
TABLE 2. Significant Differences in Parenting Variables at Baseline for MI Onset vis-à-vis Childbirth Groups

\begin{tabular}{|c|c|c|c|c|}
\hline Dependent variables & $\begin{array}{l}\text { Comparative } \\
\text { statistic }\end{array}$ & $\begin{array}{l}\text { MI onset first } \\
\quad(N=78)\end{array}$ & $\begin{array}{l}\text { Parenting first } \\
\quad(N=154)\end{array}$ & $\begin{array}{l}\text { Proximal Onset } \\
\qquad(N=109)\end{array}$ \\
\hline Explanatory parenting style ${ }^{c}$ & $F=4.864^{* *}$ & $2.577^{a}$ & $2.179^{a, b}$ & $2.017^{b}$ \\
\hline Meaning of motherhood-child as burden ${ }^{c}$ & $F=4.535^{*}$ & $0.174^{a}$ & $-0.193^{b}$ & $0.096^{a, b}$ \\
\hline Social support—persons providing child care $(\text { enacted })^{c}$ & $F=3.311^{*}$ & $2.291^{a}$ & $1.840^{a}$ & $1.790^{a}$ \\
\hline Social support—persons available for child care ${ }^{c}$ & $F=3.212 *$ & $3.100^{a}$ & $2.510^{a}$ & $2.560^{a}$ \\
\hline
\end{tabular}

schizoaffective disorder than mothers in the parenting-first group, who were more likely to have a major depression diagnosis. All three groups differed significantly on age at MI onset: MI first was the youngest, proximal onset was next, and parenting first was the oldest. Consequently, mothers with MI first had a significantly longer duration of MI than the proximal-onset group, which, in turn, had significantly greater duration than the parenting-first group. Number of lifetime hospitalizations was significantly lower for the parenting-first group compared with the others. On services variables, the only significant difference was that mothers with MI first indicated the need for a greater number of additional mental health services compared with the parenting-first group. All the above differences were maintained even when each of the following potentially confounding variables was controlled: mother's age, age at onset, and mother's educational level. There were no significant differences at baseline across the three groups on adjusted income, prior-year hospitalizations, service satisfaction, or utilization.

\section{Differences Across Groups on Parenting Variables}

Table 2 presents ANOVA and $\chi^{2}$ test results comparing the three groups on parenting variables at baseline. Signifi- cant differences were found for explanatory parenting style, meaning of motherhood/child as burden, and social support for childcare (enacted and available). Explanatory parenting style was more prevalent among mothers with MI first than among those whose onset was proximal to the birth of a child. The MI-first group also scored higher than the parenting-first group on the meaning of motherhood/child as burden measure. Finally, although the ANOVAs on social support for childcare (enacted and available) were significant, paired comparisons failed to indicate significant differences between groups. All the differences described above were maintained even when controls were added for mother's age, age at onset, and mother's educational level. No significant differences were found for other parenting measures at baseline (parenting stress, nurturance, satisfaction with relationship with children, meaning of motherhood/positive parenting, or social support for parenting feedback - enacted or available). No significant differences across groups were found for changes over time on any of the parenting measures.

\section{Differences Across Groups on Symptomatology and Community Functioning}

For symptomatology and community functioning, no differences across groups were found at baseline (Table 3).

TABLE 3. Descriptive Statistics on Functioning and Symptomatology at Each Time-point, by MI Onset vis-à-vis Childbirth Groups

\begin{tabular}{|c|c|c|c|}
\hline & $\begin{array}{l}\text { MI onset first } \\
\text { Mean }(S D)\end{array}$ & $\begin{array}{l}\text { Parenting first } \\
\text { Mean (SD) }\end{array}$ & $\begin{array}{c}\text { Proximal onset } \\
\text { Mean (SD) }\end{array}$ \\
\hline Community functioning $^{a} @ \mathrm{~T} 1$ & $3.39(0.63)$ & $3.35(0.52)$ & $3.40(0.51)$ \\
\hline Community functioning@ T2 & $3.53(0.57)$ & $3.57(0.49)$ & $3.52(0.61)$ \\
\hline Community functioning@ @3 & $3.46(0.54)$ & $3.55(0.50)$ & $3.40(0.63)$ \\
\hline Symptomatology ${ }^{b} @ \mathrm{~T} 1$ & $2.87(0.80)$ & $2.88(0.81)$ & $2.74(0.87)$ \\
\hline Symptomatology@ @2 & $2.66(0.76)$ & $2.57(0.71)$ & $2.62(0.89)$ \\
\hline Symptomatology@ T3 & $2.62(0.78)$ & $2.43(0.73)$ & $2.65(0.85)$ \\
\hline \multicolumn{4}{|c|}{$\begin{array}{l}{ }^{a} \text { Community Functioning Scale, } 5 \text {-point response scale }(1=\text { no activity in domain to } 5=\text { frequent } \\
\text { independent activity). } \\
{ }^{b} \text { Colorado Symptom Index, } 5 \text {-point response scale }(1=\text { never/not at all in the last year to } 5=\text { at least every } \\
\text { day/most of the time). }\end{array}$} \\
\hline
\end{tabular}


TABLE 4. Multilevel Model Results of the Effect of MI Onset vis-à-vis Childbirth Group on Changes in Functioning and Symptomatology

\begin{tabular}{|c|c|c|c|c|}
\hline \multirow[b]{2}{*}{ Dependent variables } & \multicolumn{2}{|c|}{ Symptomatology } & \multicolumn{2}{|c|}{$\begin{array}{l}\text { Community } \\
\text { functioning }\end{array}$} \\
\hline & Estimate & $S E$ & Estimate & $S E$ \\
\hline \multicolumn{5}{|l|}{ Random effects } \\
\hline Intercept (time 1) & $2.616 * * *$ & 0.170 & $3.422 * * *$ & 0.112 \\
\hline Time (linear change) & $0.087^{t}$ & 0.048 & 0.057 & 0.045 \\
\hline \multicolumn{5}{|l|}{ Fixed effects } \\
\hline Time squared (quadratic change) & & & $-0.029 * * *$ & 0.008 \\
\hline Age at onset (effect on time 1) & 0.036 & 0.619 & 0.024 & 0.407 \\
\hline Age at onset $\times$ year (effect on linear change) & $-0.395^{*}$ & 0.174 & 0.168 & 0.126 \\
\hline \multicolumn{5}{|l|}{ MI onset vs. childbirth group } \\
\hline MI onset 1st vs. pre/postpartum (effect on time 1) & 0.169 & 0.121 & -0.017 & 0.079 \\
\hline Parenting 1st vs. pre/postpartum (effect on time 1) & 0.174 & 0.108 & -0.050 & 0.071 \\
\hline MI onset 1st vs. pre/postpartum $\times$ year (effect on linear change) & $-0.078^{*}$ & 0.034 & 0.038 & 0.025 \\
\hline Parenting 1st vs. pre/postpartum $\times$ year (effect on linear change) & $-0.079 * *$ & 0.030 & $0.045^{*}$ & 0.022 \\
\hline
\end{tabular}

However, MLM did find differential changes over time for the three groups. Table 4 presents the MLM results controlling for mother's age of onset (due to its empirical and theoretical significance). For symptomatology, the quadratic change term was not significant in the unconditional baseline model, and it was dropped, leaving a random (i.e., varying across individuals) linear trajectory for this variable. The MLM found no significant differences between the three groups at wave 1 (the intercept), but the analysis did indicate a significant difference in the linear slopes: symptoms declined over time for all three groups, but the decline was significantly greater for the MI-first and the parenting-first groups compared with the proximal-onset group, which had a flatter change trajectory. For community functioning, both the linear and quadratic slopes were significant in the unconditional baseline model, suggesting that although there was a general linear trend from $\mathrm{W} 1$ to $\mathrm{W} 3$, the rate of change tended to slow rather than remaining constant over time. With three measurement points, the model was limited to a single random slope; because the rate of linear change varied significantly across individuals, it was modeled as a random slope. There was relatively little random variation across individuals in the rate of deceleration, so the quadratic term was entered as a fixed predictor. As with symptomatology, the MLM found no significant differences in the intercepts (W1) of the three groups. However, there was again a significant difference in the linear trajectory over time, with the parenting-first group showing a significantly greater increase in functioning compared with the proximal-onset group. These analyses were also conducted with controls for mother's age, education, and number of children less than age 18 , with no substantive differences in results.

\section{DISCUSSION}

In this study, we examined the timing of childbirth in relationship to MI onset in a sample of seriously mentally ill mothers. We identified three groups of women; a fourth group (less than 10\%) did not fit into any of the expected categories. In terms of the relative size of the three groups, the smallest proportion of the sample (approximately 20\%) experienced MI onset before the birth of any of their children (average, 5 years before). The largest proportion of mothers (approximately $40 \%$ ) had been parenting and then experienced MI onset (age of youngest child at onset was 6-7 years). Nearly $30 \%$ of the sample had experienced the onset of their serious, long-term MI in proximity to the birth of a child. This proportion is higher than that reported in other studies on MI occurring during the pre/postpartum period (Hearle and McGrath, 2000; Wisner et al., 1993). It may reflect sample differences, in that most previous studies reported demographics of women at the point they were admitted to a psychiatric hospital, while our sample was community-based and spanned multiple, lifetime hospitalizations. Also, in our sample, women were in the proximal-onset category if their onset was associated with the birth of any child rather than only the first, which could increase the number in this category. Our finding that the greatest number of women experienced parenting first is consistent with that reported by Caton et al. (1999), who also used a communitybased sample. 
The results indicate the heterogeneity among the mothers in this sample, but our subgroupings did explain some of the variation. Some of the differentiating features of the subgroups fit expected patterns: mothers who had a later onset of SMI were older, had the fewest lifetime psychiatric hospitalizations, and were more likely to be married and to have a depression diagnosis. Women who experienced early onset of MI before any children were born were more likely to have never married, to have schizophrenia or schizoaffective diagnoses, and to have a greater number of lifetime hospitalizations. These differences correspond to expectations, based on the known epidemiology of psychiatric disorders in women. However, the characteristics of SMI mothers in the proximal-onset group did differ from expectations, in that they were youngest at first childbirth, had the highest proportion of African American subjects, and had the greatest number of children.

Of greater significance, we explored whether there would be differential outcomes for women depending on the timing of MI onset in relationship to the births of their children. At baseline, women in the parenting-first group were least likely to see their children as burdens. Over the course of the study, the parenting-first group had the most significant improvements in symptomatology and community functioning. Women in the MI first group were most likely to see their children as burdens at W1. However, they were also likely to use a more appropriate (authoritative) parenting style. The MI first group also showed more improvement in symptomatology over time compared with the proximal-onset group.

That the functioning of the MI onset-first group at baseline was comparable to that of the other two groups appears counterintuitive, given the rehabilitation literature. This result may be due to specific characteristics of our sample. Women with SMI and an early onset (e.g., under age 21 ), who were still parenting when their children were preschoolers (as in our sample) may be a somewhat select group; that is, they are more educated, and their children were born later. Mothers who had experienced early MI onset and became parents, but did not retain custody of children, have abortions, or give their children up for adoption would not be in our study, as we required some parenting responsibility for a child age 4 to 18 as an eligibility criterion. Thus, it may be that the study sample of women with early-onset MI were those with the highest functioning and so were able to carry out parenting. For these mothers with MI onset first, their significantly higher burden score on the meaning of motherhood variable may actually reflect a more realistic appraisal of their situation (as a low-income mother struggling with a chronic illness) versus an overly negative attitude. This interpretation is corroborated by the fact that there were no differences across groups in terms of the positive parenting score on the meaning of motherhood variable.
We found that women with MI onset proximal to the birth of a child had poor outcomes. In terms of changes in their symptomatology and community functioning over time, the proximal-onset group showed significantly less improvement compared with the other groups. Overall, this group might be seen as the most chronic and problematic in their role functioning.

Of course, the limitations of this study need to be acknowledged. Since this was not an epidemiological study, the numbers of women identified in the groups may not reflect accurate population estimates. The identification of participants was done in a systematic fashion in an attempt to enroll all eligible mothers; however, the sample was taken only from mental health agencies in one geographical area, and therefore, results will not necessarily generalize to other parts of the United States. Next, because only years and not precise dates for first onset of psychiatric illness were available, we could not determine in our proximal-onset group whether onset occurred during pregnancy or in the postpartum period. Also, while the study was longitudinal, three data collection points are quite minimal in assessing individual trajectories, even using MLM analyses. If more time points and/or a longer time frame had been available, the results might indicate that the proximal-onset group eventually caught up with the others, or that one of the other two groups displayed a more variable pattern of functioning. Finally, while we did have a sample of mothers with MI that was much larger than most, there were more than $20 \%$ of women deemed eligible during sample selection who were not enrolled as study participants. Obviously, this has implications for the generalizability of the findings, even in this urban area.

\section{Implications}

Children of mothers with SMI are likely to be at risk for later psychiatric disorders due to both familial and environmental factors. However, some of these children do relatively well in terms of their outcomes. Thus, service providers could benefit from having more indicators to suggest which children may be at greater risk. From our study, it appears that parenting may be most problematic for those women for whom MI onset occurs in temporal proximity to the birth of a child. A sizable proportion of mothers in our sample was in this group. These women have lower education levels and show significantly less improvement over time in functioning and symptomatology, even with treatment. They also have the largest number of children, and many of the women have subsequent children after their MI onset. Clinical literature indicates that once a woman has a postpartum psychosis, the probability of having another episode is about one in three (Parry, 1999). As unfortunately was the case in some high-profile criminal cases, children of mothers with postpartum MI may additionally be at risk for serious harm or 
neglect. Women in high-risk categories (low education, low income, family history of MI) should be screened during pregnancy and after for early warning symptoms of psychiatric illness (see, for example, Cooper et al., 1996). Women who experienced MI onset proximal to the birth of a child should have much more attention paid to receipt of ongoing, intensive MI treatment, with special focus on parenting and childbirth decisions.

The mothers with onset of MI before their children were born, contrary to expectations, appear to be functioning quite well. However, additional research is needed to determine whether, in fact, this group is representative of mothers with early-onset MI. We suspect that many women with an early onset may typically lose or relinquish custody of their children when they become mothers, and so not be engaged in parenting at all. More longitudinal research is needed, starting from the point at which a woman with an early onset, long-term MI becomes pregnant and has a child, to determine differences in custody loss and/or parenting outcomes over time and their predictors. Women with early MI onset who become mothers definitely need interventions and support. In this study, these mothers were receiving services, and many appeared to be successfully parenting their children.

In our study, we also found a large number of mothers who experienced later-onset MI (especially with affective disorders). Over the course of the study, as most received continued treatment, their prognosis seemed positive. However, perhaps some earlier intervention in these women's lives could have prevented the onset of SMI entirely. More long-term research is needed on mothers in high-risk parenting situations (e.g., minority race/ethnicity, low income levels, urban environments) to help determine the particular risk and protective factors for having a diagnosable $\mathrm{MI}$ and also to examine the factors that predict these at-risk mothers' accessing and receiving mental health services.

This research also has implications for future study designs and methodologies. The results of the current analyses provide some empirical evidence of the relevance of examining timing of MI onset vis-à-vis childbirth. We therefore recommend that studies of mothers with MI collect detailed information on the timing of MI onset for each research participant in relationship to the birth of her children, to determine whether onset occurred before any pregnancies, well after all childbirths, or during a pregnancy or the postpartum period. We would also note that the current analyses again highlight the importance of longitudinal research and of using the most sophisticated methods to analyze changes over time. Examining only baseline data would have been insufficient to make conclusions about these women's functioning; the longitudinal analysis provided more definitive information for a relative comparison of the three groups.

\section{REFERENCES}

Abidin RR, Wilfong E (1989) Parenting stress and its relationship to child health care. Child Health Care. 18:114-116.

Barrera M (1986) Distinctions between social support concepts, measures and models. Am J Commun Psychol. 14:413-445.

Baumrind D (1991) The influence of parenting style on adolescent competence and substance use. $J$ Early Adolesc. 11:56-95.

Beardslee WR, Salt P, Versage EM (1997) Sustained change in parents receiving preventive interventions for families with depression. Am J Psychiatry. 154:510-515.

Broitman M, Coiro MJ, Riley AW (2001) Living with a Depressed Mother: Burden on the Child. San Francisco (CA): Annual Convention of the Am. Psych. Assoc.

Bryk AS, Raudenbush SW (1992) Hierarchical Linear Models. Newbury Park: Sage.

Bybee D, Mowbray C, Oyserman D, Lewandowski L (2003) Variability in community functioning of mothers with serious mental illness. J Behav Health Serv Res. 30:269-289.

Caton CLM, Cournos F, Dominguez B (1999) Parenting and adjustment in schizophrenia. Psychiatr Serv. 50:239-243.

Cogill SR, Caplan HL, Alexandra H, Robson KM, Kumar R (1986) Impact of maternal postnatal depression on cognitive development of young children. BMJ. 292:1165-1167.

Cooper PJ, Murray L, Hooper R, West A (1996) The development and validation of a predictive index for postpartum depression. Psychol Med. 26:627-634.

Fenton WS (2000) Heterogeneity, subtypes and longitudinal course in schizophrenia. Psychiatr Ann. 30:638-644.

Fox J (1997). Applied Regression Analysis, Linear Models and Related Methods. Thousand Oaks (CA): Sage.

Gibaud-Wallston J, Wandersman LP (1978) Development and Utility of the Parenting Sense of Competence Scale. Paper presented at Amer. Psych. Assoc., Toronto.

Goodman SH, Adamson LB, Riniti J, Cole S (1994) Mothers' expressed attitudes: Associations with maternal depression and children's self-esteem and psychopathology. J Am Acad Child Adolesc Psychiatry. 33: $1265-1274$.

Goodman SH, Brumley HE (1990) Schizophrenic and depressed mothers: Relational deficits in parenting. Devel Psychol. 26:31-39.

Gordon D, Burge D, Hammen C, Adrian C, Jaenicke C, Hiroto D (1989) Observations of interactions of depressed women with their children. Am J Psychiatry. 46:50-55.

Greden JF (2001) Treatment of Recurrent Depression. Washington DC: APA.

Harding CM, Keller AB (1998) Long-term outcome of social functioning. In KT Mueser, N Tarrier (Eds), Handbook of Social Functioning in Schizophrenia (pp 134-148). Needham Heights (MA): Allyn \& Bacon.

Hearle J, McGrath J (2000) Motherhood and schizophrenia. In D Castle, J McGrath, J Kulkarni (Eds), Women and Schizophrenia (pp 79-94). Melbourne: Cambridge University Press.

Hipwell AE, Kumar R (1996) Maternal psychopathology and prediction of outcome based on mother-infant interaction ratings (Bmis). Br J Psychiatry. 169:655-661.

Inoff-Germain G, Nottelmann ED, Radke-Yarrow M (1997) Relation of parental affective illness to family, dyadic and individual functioning: An observational study of family interaction. Am J Orthopsychiatry. 67:433-448.

Jaccard J, Wan CK (1996) LISREL Approaches to Interaction in Multiple Regression. Thousand Oaks (CA): Sage.

Jacobsen LK, Rapoport JL (1998) Research update: Childhood-onset schizophrenia: Implications of clinical and neurobiological research. $J$ Child Psychol Psychiatry. 39:101-113.

Mowbray CT, Schwartz S, Bybee D, Spang J, et al. (2000) Mothers with mental illness: Stressors and resources for parenting and living. Fam Soc. $81: 118-129$.

Nicholson J, Biebel K, Hinden B, Henry A, Stier L (2001) Critical Issues for Parents With Mental Illness and Their Families. Worcester (MA): Center for MH Services Research.

Oyserman D, Bybee D, Mowbray CT, Kahng S (2004) Parenting selfconstruals of mothers with a serious mental illness: Efficacy, burden, and personal growth. J Appl Soc Psychol. 34(12):2503-2523. 
Oyserman D, Mowbray CT, Meares PA, Firminger KB (2000) Parenting among mothers with a serious mental illness. Am J Orthopsychiatry. 70:296-315

Parry B (1999) Postpartum depression in relation to other reproductive cycle mood changes. In LJ Miller (Ed), Postpartum Mood Disorders (pp 21-45). Washington DC: APA.

Pfuhlmann B, Franzek E, Beckmann H, Stober G (1999) Long-term course and outcome of severe postpartum psychiatric disorders. Psychopathology. 32:192-202.

Philipps LHC, O’Hara MW (1991) Prospective study of postpartum depression: 4-1/2 year follow-up of women and children. J Abnorm Psychol. 100:151-155.

Puckering C (1989) Annotation: Maternal depression. J Child Psychol Psychiatry. 30:807-817.

Rickel AU, Biasatti LL (1982) Modification of the Block Child-Rearing Practices Report. J Clin Psychol. 38:129-134.

Righetti-Veltema M, Conne-Perreard E, Bousquet A, Manzano J (2002) Post-partum depression and mother-infant relationship at 3 months old. $J$ Affect Disord. 70:291-306.

Robins LN, Helzer JE, Croughan J, Ratcliff KS (1981) NIMH Diagnostic Interview Schedule: Its history, characteristics and validity. Arch Gen Psychiatry. 38:381-389.

Robling SA, Paykel ES, Dunn VJ, Abbott R, Katona C (2000) Long-term outcome of severe puerperal psychiatric illness. Psychol Med. 30:1263-1271.

Rutter M (1994) Stress research: Accomplishments and tasks ahead. In RJ Haggerty, LR Sherrod, N Garmezy, M Rutter (Eds), Stress, Risk, and Resilience in Children and Adolescents: Processes, Mechanisms and Interventions (pp 354-386). New York: Cambridge University.

Sharp D, Hay DF, Pawlby S, Schmuecker G, et al. (1995) The impact of postnatal depression on boys' intellectual development. J Child Psychol Psychiatry. 36:1315-1336.

Shern DL, Wilson NZ, Coen AS, Patrick DC, Foster M, Bartsch DA (1994) Client outcomes, II. Milbank Q. 72:123-148.

Stoolmiller M, Duncan TE, Bank L, Patterson GR (1993) Some problems and solutions in the study of change: Significant patterns in client resistance. J Consult Clin Psychol. 61:920-928.

Strauss JS, Hafez H, Lieberman P, Harding CM (1985) The course of psychiatric disorder, III: Longitudinal principles. Am J Psychiatry. 143: 289-296.

Streiner DL (2003) Being inconsistent about consistency: When coefficient alpha does and doesn't matter. J Pers Assess. 80:217-222.

Tsang H, Lam P, Darasi B, Ng B, Chan F (2000) Predictors of post-hospital employment status for persons with psychiatric disability. Psych Rehab J. 24:169-173.

US Bureau of the Census (1997) Poverty Thresholds in 1996 by Size of Family and Number of Related Children Under 18 Years. 17 October 1997. Available at: http://www.census.gove/hhes/poverty/threshld/ thresh96. html.

Vartiovaara A, Maekelae S, Pykaelaeinen R (1990) Effects of parental schizophrenia on children's mental health. Psychiatr Fennica. 21:87-103.

Wisner KL, Peindl K, Hanusa BH (1993) Relationship of psychiatric illness to childbearing status: A hospital-based epidemiologic study. J Affect Disord. 28:39-50.

Wisner KL, Peindl KS, Hanusa BH (1995) Psychiatric episodes in women with young children. J Affect Disord. 34:1-11.

Yarden PE, Max DM, Eisenbach Z (1966) Effect of childbirth on prognosis of married schizophrenic women. Br J Psychiatry. 112:491-499. 